\title{
Maternal body composition in relation to infant birth weight and subcutaneous adipose tissue
}

\author{
Elisabet Forsum $^{1 *}$, Marie Löf ${ }^{1}$, Hanna Olausson ${ }^{1}$ and Elisabeth Olhager ${ }^{2}$ \\ ${ }^{1}$ Department of Biomedicine and Surgery, Division of Nutrition, University of Linköping, SE-581 85 Linköping, Sweden \\ ${ }^{2}$ Department of Molecular and Clinical Medicine, Division of Paediatrics, University of Linköping, University Hospital, \\ SE-581 85 Linköping, Sweden
}

(Received 13 September 2005 - Revised 29 March 2006 - Accepted 5 April 2006)

\begin{abstract}
Infant birth weight has increased recently, representing an obstetric and potentially a public health problem since high birth weight involves a risk of obesity later in life. Maternal nutritional status is important for fetal growth and therefore relationships between maternal body weight and composition $v$. birth weight and infant subcutaneous adipose tissue were investigated in twenty-three healthy women and their newborn infants using multiple and simple linear regression analysis. Furthermore, using previously published data for nineteen infants, it was demonstrated that an anthropometric method could provide useful estimates of the amount of subcutaneous adipose tissue. Birth weight was correlated with the maternal content of total body fat (TBF) both before pregnancy and in gestational week 32 and, together with gestational age at birth, TBF (\%) before pregnancy explained $45 \%$ of the variation in birth weight. This figure was not increased when gestational gains in weight or TBF were added to the model. Furthermore, in infants, birth weight correlated with the amount of their subcutaneous adipose tissue. Together maternal TBF (\%) and amount of subcutaneous adipose tissue in infants explained $61-63 \%$ of the variation in birth weight while the amount of infant subcutaneous adipose tissue alone explained only $55 \%$. The maternal TBF content is likely to be important for the recent increase in birth weight. This factor probably causes a general augmentation in fetal growth rather than a specific stimulation of adipose tissue growth.
\end{abstract}

Birth weight: Maternal nutritional status: Subcutaneous adipose tissue: Total body fat

The relationship between the nutritional status of women and reproductive outcome, for example infant birth weight, is well recognized (Coad, 2003). However, our knowledge about the factors important for fetal growth is unfortunately incomplete, although it is known that genetics and nutrition are involved. During recent years the average birth weight has increased in many countries (Meeuwisse \& Otterblad Olausson, 1998; Kramer et al. 2002; Odlind et al. 2003), representing increased health risks for infants and for mothers at delivery (Surkan et al. 2004). Furthermore, a high birth weight is associated with an increased risk of obesity later in life (Stettler et al. 2002; Dietz, 2004), which is potentially a very serious problem since diseases related to obesity are major causes of morbidity and death in many populations. Reports (Kramer et al. 2002; Surkan et al. 2004) linking a concurrent increase in maternal BMI to the observed increase in birth weight motivate further studies of how the maternal nutritional situation influences fetal growth and development. Maternal preconceptional body weight and composition, as well as gestational weight gain, are known to be important (Villar et al. 1992; Butte et al. 2003; Thame et al. 2004) in this context, and the gestational weight gain recommended by the Institute of Medicine (1990) differs for women with different BMI. Prepregnant BMI is generally considered to reflect the maternal nutritional status since BMI is related to the total body fat (TBF) content although the relationship between TBF and BMI is not perfect (Gallagher et al. 2000). Furthermore, for a long time the specific components of gestational weight gain that are critical for fetal growth were not clearly delineated, mainly due to difficulties involved in the measurement of body composition during pregnancy. Using appropriate techniques, Butte et al. (2003) recently found that birth weight was correlated with gestational gain in weight but not with gestational gain in TBF. However, their estimate of gestational weight gain explained only a small proportion of the variation in birth weight and by including pre-pregnancy weight and gestational age a larger proportion of this variation could be explained (Butte et al. 2003). It seems likely that this observation, at least partly, was a consequence of the pre-pregnant maternal TBF content, since a significant correlation between this content (in $\mathrm{kg}$ ) and infant birth weight was also reported (Butte et al. 2003).

When studying the intrauterine origins of obesity the body composition of newborns becomes of interest. In this context information regarding the amount of adipose tissue in the infant body as well as its fat content is relevant. Such information is often obtained using a so-called skin fold caliper. Obviously this device provides an estimate of the thickness 
of subcutaneous (s.c.) adipose tissue while a recent report demonstrates that such estimates do not represent useful estimates of TBF in infants (Olhager \& Forsum, 2006). We have previously described a method by which the subcutaneous adipose tissue volume (s.c. ATV) in the infant body can be identified and assessed in vivo (Olhager et al. 1998) using magnetic resonance imaging (MRI) and such estimates (s.c. ATV-MRI) have been reported for healthy infants under 4 months of age (Olhager \& Forsum, 2003; Olhager et al. 2003). Furthermore, Kabir \& Forsum (1993) have described an anthropometric method by which the s.c. ATV can be assessed on the basis of measurements obtained using a tape measure and a skin fold caliper and in this paper estimates of s.c. ATV obtained using this method (s.c. ATV-Kabir) are compared with s.c. ATV-MRI. In addition, we have previously presented a mother-infant study describing the body composition of healthy women before, during and shortly after pregnancy, as well as the birth weight of their infants (Löf \& Forsum, 2004; Löf et al. 2005). The results were obtained using methodology appropriate for estimating body composition of women during reproduction. The newborn infants were investigated with regard to their s.c. ATV-Kabir. Consequently, the data could be used to study relationships between maternal weight and body composition variables, on the one hand, and infant weight and amount of s.c. adipose tissue on the other, and these data are reported later. In particular, the present paper addresses the hypothesis that the maternal body fat content stimulates growth of the fetus and its adipose tissue.

\section{Materials and methods}

Study of the validity of the Kabir subcutaneous adipose tissue volume assessment method

Nineteen infants (eleven full term and eight preterm), 4-75d old, were investigated with regard to their body weight, TBF, s.c. ATV-MRI, s.c. ATV-Kabir and the average of ten skin folds. For each infant, all these estimates were assessed in $1 \mathrm{~d}$. These infants were part of a larger study (Olhager \& Forsum, 2003; Olhager et al. 2003) where the ATV of infants was investigated. The nineteen infants were included in the present study since their s.c. ATV-Kabir results were comparable with those found for the infants in the mother-infant study.

\section{Mother-infant study}

Twenty-three healthy women, with parity of zero to two and planning pregnancy, participated in the present study (Löf \& Forsum, 2004, 2006; Löf et al. 2005). When a woman had conceived, gestational age was estimated on the basis of an ultrasound measurement, generally in gestational week 12 (Jörgensen, 1997). Each woman delivered one healthy baby. Body weight, TBF and fat-free weight of the women were assessed before pregnancy, in gestational week 32 and 2 weeks postpartum. Their body weight was also measured in the delivery room prior to childbirth. Fetal weight was assessed by means of ultrasound in gestational week 31 (Jörgensen, 1997). In the infants, birth weight was recorded shortly after delivery, while ten skin folds, s.c. ATV-Kabir and body weight were assessed at the age of $3 \pm 2 \mathrm{~d}$.

\section{Methods}

For assessing TBF of the women, a two-component model based on total body water was used as previously described (Löf \& Forsum, 2004). Fat-free weight was calculated from total body water using the hydration factors $0.718,0.747$ and 0.734 before pregnancy, in gestational week 32 and postpartum, respectively (Löf \& Forsum, 2004). TBF was body weight minus fat-free weight. Weight of the babies was assessed using an electronic baby scale (Tanita Corporation, Tokyo, Japan). The procedures used to assess s.c. ATV-MRI (Olhager et al. 1998, 2003; Olhager \& Forsum, 2003) and TBF ('TBF-BWD' by isotope dilution) (Olhager \& Forsum, 2006) of the infants in the study of validity of the Kabir s.c. ATV assessment method have been described previously. In the isotope dilution method ${ }^{2} \mathrm{H}$ and ${ }^{18} \mathrm{O}$ were used as tracers and calculations were based on zero-time enrichments obtained from isotope disappearance curves. Corrections for non-aqueous exchange were made and total body water was the average of results obtained for the two isotopes. s.c. ATV-MRI was assessed with a precision of $1.6 \%$ (Olhager et al. 2003). The following ten skin folds were assessed (Harrison et al. 1988) and their average was calculated: triceps; biceps; forearm; subscapula; mamilla; abdomen; calf; buttock; back and front of thigh. All skin folds were assessed in duplicate and, on the basis of these estimates, the technical error of measurement (Ulijaszek \& Kerr, 1999) was calculated to be $0.3-0.5 \mathrm{~mm}$ for all skin folds except back of thigh and buttock where this error was $0.7-0.9 \mathrm{~mm}$. Together with estimates of arm, leg, head and trunk circumferences and arm, leg, crownrump and body lengths, these skin folds were used to calculate s.c. ATV (s.c. ATV-Kabir) using a modification of the method described by Dauncey et al. (1977). In this calculation a model of the infant body is made up of a sphere (the head), a large cylinder (the trunk) and two pairs of smaller cylinders (arms and legs). The head is assumed to contain no s.c. ATV. The amount of s.c. ATV on the trunk $(A)$ is the trunk length (crown-rump length minus head circumference divided by 3.14) times trunk circumference (average of chest and hip circumference) times the average of ten skin folds $/ 2$ minus $0 \cdot 1$. The amount of s.c. ATV on the arm $(B)$ is the length of the arm times arm circumference (average of lower and upper arm circumferences) times the average of ten skin folds $/ 2$ minus $0 \cdot 1$. The amount of s.c. ATV on the leg $(C)$ is the length of the leg (body length minus crown-rump length) times leg circumference (average of calf and thigh circumferences) times the average of ten skin folds $/ 2$ minus $0 \cdot 1$. All estimates were expressed in $\mathrm{cm}$ and obtained using a tape measure, a length board or a Harpenden skin fold caliper (Practical Metrology, Lancing, UK). s.c. ATV-Kabir was calculated as $A+2 B+2 C$.

\section{Ethics}

The data reported in the present paper were obtained from studies (Olhager \& Forsum, 2003; Olhager et al. 2003; Löf \& Forsum, 2004, 2006; Löf et al. 2005) approved by the ethics committee of the University of Linköping. 


\section{Statistics}

Values are means and standard deviations. Linear and multiple regression analyses were performed as described by Hassard (1991). Significance was accepted at the $P<0.05$ level. All statistical analyses were carried out using Statistica software, version 6.0 (StatSoft, Scandinavia AB, Uppsala, Sweden). Estimates of s.c. ATV-Kabir were evaluated according to Bland \& Altman (1995). Thus the average and limits of agreement $(2 \mathrm{SD})$ for the difference between s.c. ATV-Kabir and s.c. ATV-MRI, as well as the correlation between this difference and the average of s.c. ATV-Kabir plus s.c. ATV-MRI, were calculated.

\section{Results}

\section{Subjects}

Information regarding infants in the study of validity of the Kabir s.c. ATV assessment method is presented in Table 1, while Table 2 shows characteristics of the subjects in the mother-infant study.

Study of the validity of the Kabir subcutaneous adipose tissue volume assessment method

For infants in the study of validity of the Kabir s.c. ATV assessment method, a significant correlation was obtained between the average of ten skin folds and s.c. ATV-MRI in $\mathrm{ml}(r 0.78, P=0.000089)$ and in $\mathrm{ml} / \mathrm{kg}$ infant body weight ( $r$ 0.77, $P=0.000131$ ) but not between the average of ten skin folds and TBF $(\%)(r 0.37, P>0.05)$. Nor was there a significant correlation between TBF (\%) and s.c. ATV-MRI (ml/ $\mathrm{kg}$ infant body weight) $(r 0.40, P>0.05)$. s.c. ATV-Kabir $(\mathrm{ml}$, $x$ ) was significantly correlated with s.c. ATV-MRI $(\mathrm{ml}, y)$, $y=1 \cdot 25 x+260, r 0 \cdot 84, P=0.000007$. A comparison according to Bland \& Altman (1995) showed that s.c. ATV-MRI minus s.c. ATV-Kabir was $373 \mathrm{ml}$ on average and the limits of agreement was 171 (2 SD) ml. Furthermore, the following significant linear relationship was found: [(s.c. ATV-MRI) (s.c. ATV-Kabir) $]=0.428[$ [s.c. ATV-MRI) + (s.c. ATVKabir) $] / 2+99.9(r$ 0.60, $P=0.0063)$.

\section{Mother-infant study}

Size at birth $v$. maternal body weight and composition. Table 3 shows correlation coefficients for linear relationships between infant birth weight and maternal body weight and composition before and during pregnancy. Fig. 1 shows birth weight $v$. maternal TBF (\%) before pregnancy (Fig. 1 (a)) and $v$. net gestational weight gain (Fig. 1 (b)). Before pregnancy and in gestational week 32, significant correlations with maternal body weight and $\mathrm{TBF}$, in $\mathrm{kg}$ and as a percentage, were obtained. Neither retention of body weight nor of TBF during pregnancy was significantly correlated with birth weight. Furthermore, as also shown in Table 3, birth weight of the infants was significantly correlated with their gestational age at birth. In addition, TBF $(\%)$ before pregnancy was significantly $(r 0 \cdot 50, P=0 \cdot 014)$ correlated with TBF $(\mathrm{kg})$ mobilized between gestational week 32 and 2 weeks postpartum while the correlation between TBF gained during the entire pregnancy $(\mathrm{kg})$ and the amount $(\mathrm{kg})$ mobilized between gestational week 32 and 2 weeks postpartum was not significant. The maternal TBF content (\%), both before pregnancy and in gestational week 32, was not significantly correlated with the length of the infant at birth. As shown in Table 4, $\mathrm{TBF}(\%)$ before pregnancy and gestational age at birth explained $45 \%$ of the variation in birth weight. When either TBF $(\mathrm{kg})$ retained during the entire pregnancy or the net gestational weight gain $(\mathrm{kg})$ was added to this model, this figure was $42 \%$ or $44 \%$, respectively.

Fetal growth and birth weight $v$. subcutaneous adipose tissue volume of infants. Table 5 shows correlation coefficients for linear relationships between birth weight of infants $v$. the amount and thickness of their sc ATV. s.c. ATVKabir in $\mathrm{ml}$ and in $\mathrm{ml} / \mathrm{kg}$ infant body weight was significantly correlated with birth weight. Also, birth weight was significantly correlated with the average of ten skin folds and with each individual skin fold. Fetal growth $(\mathrm{g})$ between gestational week 31 and birth was significantly correlated ( $r$ 0.66, $P=0.00060)$ with the average of ten skin folds. Neither s.c. ATV-Kabir (in $\mathrm{ml}$ or in $\mathrm{ml} / \mathrm{kg}$ infant body weight) nor the average of ten skin folds was significantly correlated $(P>0.05)$ with maternal TBF ( $\mathrm{kg}$ or \%) at any of the measurements before, during and after pregnancy. Likewise, neither

Table 1. Characteristics of full term and preterm infants participating in the study of validity of the Kabir subcutaneous adipose tissue volume (s.c. ATV-Kabir) assessment method*

(Mean values, standard deviations and ranges for nineteen subjects)

\begin{tabular}{|c|c|c|c|c|c|c|c|}
\hline & \multicolumn{2}{|c|}{ Full term† } & \multicolumn{2}{|c|}{ Preterm $\ddagger$} & \multicolumn{3}{|c|}{ Full term and preterm } \\
\hline & Mean & SD & Mean & SD & Mean & SD & Range \\
\hline Age at the day of investigation (d) & 16 & 12 & 63 & 10 & 36 & 26 & \\
\hline \multicolumn{8}{|l|}{ Body weight } \\
\hline At birth (g) & 3460 & 425 & 1850 & 300 & 2780 & 895 & \\
\hline At the day of investigation $(\mathrm{g})$ & 3765 & 300 & 3350 & 250 & 3540 & 320 & \\
\hline s.c. ATV-MRI§ (ml) & 836 & 186 & 810 & 91 & 825 & 150 & $505-1119$ \\
\hline s.c. ATV-Kabir\| (ml) & 462 & 117 & 436 & 78 & 451 & 101 & $287-590$ \\
\hline Total body fat (\%) & $16 \cdot 5$ & 5.6 & $15 \cdot 8$ & $3 \cdot 1$ & $16 \cdot 2$ & 4.6 & $9 \cdot 0-28 \cdot 2$ \\
\hline Average of ten skin folds (mm) & $7 \cdot 6$ & $1 \cdot 3$ & $7 \cdot 8$ & 0.9 & $7 \cdot 7$ & $1 \cdot 2$ & $5 \cdot 8-9 \cdot 3$ \\
\hline
\end{tabular}

* For details of procedures, see p. 409

† Four boys and seven girls.

$\ddagger$ Six boys and two girls, born at a gestational age of 221 (SD 7) d.

$\S$ Assessed using magnetic resonance imaging (Olhager et al. 1998, 2003; Olhager \& Forsum, 2003)

\| Assessed according to Kabir \& Forsum (1993). 
Table 2. Characteristics of subjects in the mother-infant study*

\begin{tabular}{|c|c|c|c|}
\hline & Mean & SD & Range \\
\hline \multicolumn{4}{|l|}{ Women } \\
\hline \multicolumn{4}{|l|}{ Before pregnancy } \\
\hline Age (years) & 30 & 4 & $23-37$ \\
\hline Body weight (kg) & $67 \cdot 4$ & $12 \cdot 1$ & $51 \cdot 1-95 \cdot 0$ \\
\hline Height $(\mathrm{m})$ & 1.67 & 0.07 & $1.54-1.76$ \\
\hline BMI $\left(\mathrm{kg} / \mathrm{m}^{2}\right)$ & $24 \cdot 2$ & $4 \cdot 8$ & $18 \cdot 0-30 \cdot 0$ \\
\hline Total body fat $(\mathrm{kg})$ & $22 \cdot 6$ & 8.9 & $11 \cdot 7-40 \cdot 8$ \\
\hline Total body fat (\%) & 32.6 & $7 \cdot 8$ & $17 \cdot 2-49 \cdot 8$ \\
\hline Fat-free weight $(\mathrm{kg})$ & $44 \cdot 6$ & $5 \cdot 5$ & $35 \cdot 3-51 \cdot 8$ \\
\hline \multicolumn{4}{|l|}{ Gestational week 32} \\
\hline Body weight (kg) & $79 \cdot 3$ & $15 \cdot 6$ & $58 \cdot 1-101 \cdot 5$ \\
\hline Total body fat (kg) & $27 \cdot 0$ & 9.5 & $11 \cdot 4-46 \cdot 2$ \\
\hline Total body fat (\%) & $33 \cdot 3$ & $7 \cdot 3$ & $16 \cdot 9-47 \cdot 7$ \\
\hline \multicolumn{4}{|l|}{ Two weeks postpartum } \\
\hline Body weight (kg) & 73.5 & $13 \cdot 1$ & $51 \cdot 9-96 \cdot 6$ \\
\hline Total body fat $(\mathrm{kg})$ & $26 \cdot 7$ & $8 \cdot 5$ & $14 \cdot 4-44 \cdot 7$ \\
\hline Total body fat $(\%)$ & 35.5 & $6 \cdot 0$ & $30 \cdot 2-50 \cdot 1$ \\
\hline \multicolumn{4}{|l|}{ During pregnancy } \\
\hline Gestational weight gain† $(\mathrm{kg})$ & $18 \cdot 1$ & $6 \cdot 6$ & $7 \cdot 9-29 \cdot 1$ \\
\hline Net gestational weight gain $\ddagger(\mathrm{kg})$ & $6 \cdot 1$ & $5 \cdot 2$ & $-3 \cdot 2-15 \cdot 4$ \\
\hline Gain in total body fatł $(\mathrm{kg})$ & 3.9 & $3 \cdot 7$ & $-1 \cdot 3-8 \cdot 8$ \\
\hline \multicolumn{4}{|l|}{ Infants§ } \\
\hline Fetal weight|| (g) & 1658 & 175 & $1339-1993$ \\
\hline Birth weight $(\mathrm{g})$ & 3735 & 510 & $2600-4470$ \\
\hline Birth length $(\mathrm{cm})$ & 51 & 2 & $46-57$ \\
\hline Gestational age at birth (d) & 280 & 10 & $256-296$ \\
\hline s.c. ATV-Kabirף (ml) & 357 & 137 & $173-600$ \\
\hline Average of ten skin folds (mm) & $6 \cdot 4$ & $1 \cdot 3$ & $4 \cdot 4-8 \cdot 7$ \\
\hline Body weight** (g) & 3550 & 465 & $2510-4220$ \\
\hline $\operatorname{Age}^{\star *}(\mathrm{~d})$ & 3 & 2 & $1-7$ \\
\hline
\end{tabular}

* For details of procedures, see p. 409.

†Body weight before delivery minus body weight before pregnancy.

$\ddagger$ Value 2 weeks postpartum minus value before pregnancy.

$\S$ Nine boys and fourteen girls.

|| In gestational week 31

I Subcutaneous adipose tissue volume estimated according to Kabir \& Forsum (1993).

${ }^{*}$ When assessing subcutaneous adipose tissue volume according to Kabir \& Forsum (1993).

s.c. ATV-Kabir (in $\mathrm{ml}$ or in $\mathrm{ml} / \mathrm{kg}$ infant body weight) nor the average of ten skin folds was significantly correlated $(P>0.05)$ with the amount of TBF retained by the mother during pregnancy or with the amount of TBF she mobilized between gestational week 32 and 2 weeks after delivery. Table 4 shows that in a multiple regression analysis, the average of ten skin folds in the infants and the maternal TBF content (\%) before pregnancy were both significantly related to birth weight. Together, these two independent variables explained $61 \%$ of the variation in birth weight while the average of ten skin folds explained only $55 \%$ of this variation. Similar results were obtained when TBF $(\%)$ in gestational week 32 was used in the multiple regression analysis instead of the maternal TBF content before pregnancy (Table 4).

\section{Discussion}

It is of relevance to compare the women in our motherinfant study with the women studied by Butte et al. (2003). The present study contained only twenty-three motherinfant pairs, while the study of Butte et al. (2003) was based on at least sixty observations. On average, the women in the present study were a little heavier, gained slightly more weight during pregnancy and delivered babies with a somewhat higher birth weight. However, in both studies, significant correlations were found for birth weight $v$. maternal body weight and TBF $(\mathrm{kg})$ before pregnancy. Butte et al. (2003) found significant correlations for birth weight $v$. gestational weight gain and the coefficients of correlation, 0.35 for gestational weight gain and 0.26 for net gestational weight gain, were very similar to the corresponding figures in the present study. However, due to the small number of subjects, the power of the present study was insufficient to identify correlation coefficients below 0.42 as significant. Nevertheless, the similarity between results obtained in the present study and in the study reported by Butte et al. (2003) supports the conclusion that the present results represent valid reflections of how maternal weight and body composition affect fetal growth and birth weight. It should also be noted that the technical error of measurement associated with our skin folds may appear large, especially for two of the skin folds (back of thigh and buttock). We have been unable to find any studies in the literature that report on the precision of the skin folds measured in the present study in a similar population of very young infants. Nevertheless, as discussed later, there were strong correlations between s.c. ATV-MRI and skin fold results. 
Table 4. Multiple regression analysis with birth weight $(\mathrm{g})$ as the dependent variable, based on twenty-three mother-infant pairs*

\begin{tabular}{|c|c|c|c|c|c|c|}
\hline & Independent variables† & Intercept & $\begin{array}{l}\text { Regression coefficient } \\
(B)\end{array}$ & $P$ for $B$ & $\begin{array}{l}\text { Adjusted coefficient of determination } \\
\qquad\left(R^{2}\right)\end{array}$ & $P$ for $R^{2}$ \\
\hline \multirow[t]{3}{*}{ I } & & -4870 & & & 0.45 & 0.00107 \\
\hline & Total body fat before pregnancy $¥$ (\%) & & $24 \cdot 27$ & 0.033 & & \\
\hline & Gestational age at birth§ (d) & & $27 \cdot 89$ & 0.004 & & \\
\hline \multirow[t]{3}{*}{ II } & & 1423 & & & 0.61 & 0.00003 \\
\hline & Total body fat before pregnancy $¥$ (\%) & & $19 \cdot 33$ & 0.044 & & \\
\hline & Average of ten skin folds $\S(\mathrm{mm})$ & & $264 \cdot 7$ & 0.000089 & & \\
\hline \multirow[t]{3}{*}{ III } & & 1323 & & & 0.63 & 0.00002 \\
\hline & Total body fat in gestational week $32 \ddagger(\%)$ & & $22 \cdot 1$ & 0.028 & & \\
\hline & Average of ten skin folds§ (mm) & & $263 \cdot 8$ & 0.000071 & & \\
\hline
\end{tabular}

*For details of procedures, see p. 409.

†The independent variables were correlated in the following way: total body fat before pregnancy $v$. total body fat in gestational week $32, r 0.98, P=2 \cdot 1 \times 10^{-16}$; total body fat before pregnancy $v$. gestational age at birth, $r 0.20, P>0.05$; total body fat before pregnancy $v$. average of ten skin folds, $r 0.27, P>0.05$; total body fat in gestational week $32 v$. gestational age at birth, $r 0.31, P>0.05$; total body fat in gestational week $32 v$. average of ten skin folds, $r 0.26, P>0.05$; gestational age at birth $v$. average of ten skin folds; $r 0.42, P=0.048$

$\ddagger$ In women.

$\S$ In infants.

high birth weight is associated with increased fat free weight rather than with a high body fat content later in life. Furthermore, since infant adipose tissue apparently contains quite variable amounts of fat (Baker, 1969; Olhager \& Forsum, 2006), more comprehensive studies are needed to obtain a clear picture of how the maternal nutritional situation influences aspects of fetal growth and birth weight that are relevant in relation to intrauterine origins of obesity. Nevertheless, a likely interpretation of the present findings is that the association between the maternal TBF content and infant birth weight represents an adaptation to a situation where dietary energy has been highly available for a long period of time and where, therefore, the offspring is allowed to develop a large body, a situation that will require a comparatively large amount of food in the future, since body size has an important impact on dietary energy requirements (Food and Agricultural Organization of the United Nations, 2004). This

Table 5. Correlation coefficients $(r)$ for linear relationships between birth weight of infants $(g) v$. the amount and thickness of their subcutaneous adipose tissue, based on twenty-three infants*

\begin{tabular}{lcl}
\hline Independent variable & $r$ & \multicolumn{1}{c}{$P$} \\
\hline s.c. ATV-Kabir† (ml) & 0.81 & 0.0000031 \\
s.c. ATV-Kabir† $(\mathrm{ml} / \mathrm{kg}) \ddagger$ & 0.66 & 0.00056 \\
Average of ten skin folds $(\mathrm{mm})$ & 0.75 & 0.000033 \\
Individual skin folds $(\mathrm{mm})$ & & \\
$\quad$ Triceps & 0.71 & 0.00017 \\
Biceps & 0.43 & 0.043 \\
Forearm & 0.67 & 0.00052 \\
Subscapular & 0.74 & 0.000054 \\
Umbilicus & 0.60 & 0.0022 \\
Front of thigh & 0.74 & 0.000061 \\
Back of thigh & 0.66 & 0.00088 \\
Mamillae & 0.57 & 0.0044 \\
Buttock & 0.53 & 0.0089 \\
Calf & 0.51 & 0.014 \\
\hline
\end{tabular}

* For details of procedures, see p. 409

† Subcutaneous adipose tissue volume estimated according to Kabir \& Forsum (1993)

$\ddagger$ Infant body weight estimated when assessing subcutaneous adipose tissue volume. interpretation can be reconciled with the observation by Baker et al. (2004), who reported that the pre-pregnant BMI of women was related to the amount of weight gained by their babies during the first year of life.

\section{Acknowledgements}

This research was funded by the Swedish Research Council (project no. 12 172), the County Council of Östergötland and the following foundations: Swedish Nutrition, Crown Princess Lovisa, Knut and Alice Wallenberg, Dr P. Håkansson, Magnus Bergvall, General Maternity Hospital, Lions and Wera Ekström. We thank all the women and infants who participated in the studies.

\section{References}

Baker GL (1969) Human adipose tissue composition and age. Am J Clin Nutr 22, 829-835.

Baker JL, Michaelsen KF, Rasmussen KM \& Sorensen TIA (2004) Maternal prepregnant body mass index, duration of breastfeeding, and timing of complementary food introduction are associated with infant weight gain. Am J Clin Nutr 80, 1579-1588.

Bland JM \& Altman DG (1995) Comparing methods of measurement: why plotting difference against standard method is misleading. Lancet 346, 1085-1087.

Butte NF, Ellis KJ, Wong WW, Hopkinson JM \& O’Brian Smith E (2003) Composition of gestational weight gain impacts maternal fat retention and infant birth weight. Am J Obstet Gynecol 189, 1423-1432.

Coad J (2003) Pre- and periconceptual nutrition. In Nutrition in Early Life, pp. 39-71 [JB Morgan and JWT Dickerson, editors]. Chichester: John Wiley \& Sons.

Dauncey MJ, Gandy G \& Gairdner D (1977) Assessment of total body fat in infancy from skinfold thickness measurements. Arch Dis Child 52, 223-227.

Dietz WH (2004) Overweight in childhood and adolescence. $N$ Engl J Med 350, 855-857.

Food and Agricultural Organization of the United Nations (2004) Human Energy Requirements. Technical Report Series no. 1. Rome: FAO.

Gallagher D, Heymsfield SB, Heo M, Jebb SA, Murgatroyd PR \& Sakamoto Y (2000) Healthy percentage body fat ranges: an 
approach for developing guidelines based on body mass index. Am J Clin Nutr 72, 694-701.

Harrison GG, Buskirk ER, Carter JEL, Johnston FE, Lohman TG, Pollock ML, Roche AF \& Wilmore J (1988) Skinfold thickness and measurement technique. In Anthropometric Standardization Reference Manual, pp. 55-70 [T Lohman, AF Roche and R Martorell, editors]. Champaign, IL: Human Kinetics Books.

Hassard T (1991) Understanding Biostatistics. St Louis, MO: Mosby Year Book.

Institute of Medicine (1990) Nutrition During Pregnancy. Part I: Weight Gain, pp. 1-23 Washington, DC: National Academy Press.

Jörgensen C (1997) Fetometri och graviditetslängdbestämning. In Obstetriskt ultraljud, pp. 37-44. Västerås: Västra Aros tryckeri AB.

Kabir N \& Forsum E (1993) Estimation of total body fat and subcutaneous adipose tissue in full-term infants below 3 months old. Pediatr Res 34, 448-454.

Kensara OA, Wootton SA, Phillips DI, Patel M, Jackson AA, Elia M \& the Hertfordshire Study Group (2005) Fetal programming of body composition: relation between birth weight and body composition measured with dual-energy X-ray absorptiometry and anthropometric methods in older Englishmen. Am J Clin Nutr 82, 980-987.

Kramer MS, Morin I, Yang H, Platt RW, Usher R, McNamara H, Joseph KS \& Wen SW (2002) Why are babies getting bigger? Temporal trends in fetal growth and its determinants. $J$ Pediatr 141, 538-542.

Löf M \& Forsum E (2004) Hydration of fat-free mass in healthy women with special reference to the effect of pregnancy. Am J Clin Nutr 80, 960-965.

Löf M \& Forsum E (2006) Activity pattern and energy expenditure due to physical activity before and during pregnancy in healthy Swedish women. Br J Nutr 95, 296-302.

Löf M, Olausson H, Boström K, Sohlström A \& Forsum F (2005) Changes in basal metabolic rate during pregnancy in relation to changes in body weight and composition, cardiac output, insulinlike growth factor I, thyroid hormones and in relation to fetal growth. Am J Clin Nutr 81, 678-685.

Meeuwisse G \& Otterblad Olausson P (1998) Increasing birthweights in the Nordic countries; a growing proportion of neonates weigh over four kg. Läkartidningen 95, 5488-5492.
Odlind V, Haglund B, Pakkanen M \& Otterblad Olausson P (2003) Deliveries, mothers and newborn infants in Sweden, 1973-2000. Trends in obstetrics as reported to the Swedish medical birth register. Acta Obstet Gynecol Scand 82, 516-528.

Olhager E, Flinke E, Hannerstad U \& Forsum E (2003) Studies on human body composition during the first 4 months of life using magnetic resonance imaging and isotope dilution. Pediatr Res 54, 906-912.

Olhager E \& Forsum E (2003) Total energy expenditure, body composition and weight gain in moderately preterm and full-term infants at term postconceptional age. Acta Paediatr 92, $1327-1334$.

Olhager E \& Forsum E (2006) Assessment of total body fat using the skinfold technique in fullterm and preterm infants. Acta Paediatr 95, 21-28.

Olhager E, Thuomas K-Å, Wigström L \& Forsum E (1998) Description and evaluation of a method based on magnetic resonance imaging to estimate adipose tissue volume and total body fat in infants. Pediatr Res 44, 572-577.

Singhal A, Wells J, Cole TJ, Fewtrell M \& Lucas A (2003) Programming of lean body mass: a link between birth weight, obesity, and cardiovascular disease? Am J Clin Nutr 77, 726-730.

Stettler N, Zemel BS, Kumanyika S \& Stallings VA (2002) Infant weight gain and childhood overweight status in a multicenter, cohort study. Pediatrics 109, 194-199.

Surkan PJ, Hsieh C-C, Johansson ALV, Dickman PW \& Cnattingius S (2004) Reasons for increasing trends in large for gestational age births. Obstet Gynecol 104, 720-726.

Thame M, Osmond C, Bennet F, Wilks R \& Forrester T (2004) Fetal growth is directly related to maternal anthropometry and placental volume. Eur J Clin Nutr 58, 894-900.

Villar J, Cogswell M, Kestler E, Castillo P, Mendendez R \& Repke JT (1992) Effect of fat and fat-free mass deposition during pregnancy on birth weight. Am J Obstet Gynecol 167, 1344-1352.

Ulijaszek SJ \& Kerr DA (1999) Anthropometric measurement error and the assessment of nutritional status. Br J Nutr 82, $165-177$.

Yajnik CS, Lubree HG, Rege SS, Naik SS, Deshpande JA, Deshpande SS, Joglekar CV \& Yudkin JS (2002) Adiposity and hyperinsulinemia in Indians are present at birth. J Clin Endocrinol Metab 87, $5575-5580$. 